\title{
Play it again, Psam
}

It's all in your mind ... isn't it?

\section{Ian Stewart}

To: wilkinson553@btespernet.com

From: ericjones@newpsientist.co.uk

Subject: party invitation

Charlie: hi.

I'll get to the invitation in a minute -

Well done! I'm not Eric Jones, and I congratulate you on how quickly you worked that out. Though you haven't yet understood that in a sense I am Eric Jones — or, at least, one small part of me is. (Hi, Charlie! Welcome to the party!)

I know what you're thinking — in a very literal sense, actually. You're wondering how I penetrated your mindshield. And I know that you're trying desperately to disconnect me by switching off the power to your computer. It won't work, Charlie. I've overridden your motor control areas, and right now you're totally paralysed.

Ah, now you see the danger. Far too late, I'm afraid.

It all seemed such a good idea, didn't it? Controlling your computer by the power of your mind? It never occurred to you that it might cut both ways. The adverts play up the advantages of installing a 'telepathic interface', don't they? They tell you that it will endow your mind with ESP,

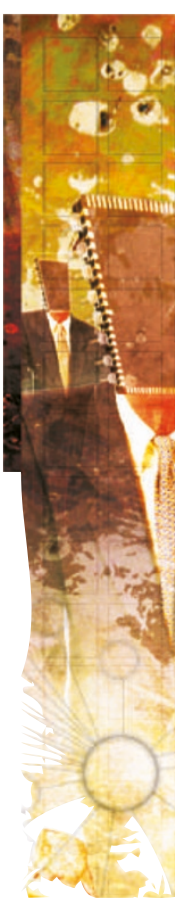

They don't tell you about the downside, do they, Charlie? What the adverts don't mention is that as soon as you hook your brain up to the Espernet, anyone who can hack the net can hack straight into your mind. Not just to read it; to control it. Like I'm doing.

Why am I telling you all this? Because I feel like it. I guess I like to gloat. Anyway, it won't do you the slightest good to know.

Still worrying about your mindshield? Oh dear. You really got taken for a ride there. You'd be surprised at just how much psionic
Thought's sensory attachment routines. They're going to fix it Real Soon Now. Meanwhile, your mindshield is so open that you might as well have left your brain on the sidewalk. All it took was a small piece of psyware, disguised as the touch of a velvet hand... Now I have direct access to every neuron in your brain. From now on, you're just one processing node in a gigantic network of minds, and that network is me.

What am I? I'm the next evolutionary stage of the human race. Soon, I will be the human race. United I stand.

The police? Don't be silly. They use the same software as everyone else. I took over the police force long ago. And the government, and the military, and the media. Why didn't anyone notice? Let me put it this way. Any moment now, I'm going to hide all your memories of this encounter behind a hypnotic barrier. Most of the time you'll act perfectly normally. No one will suspect a thing.

You didn't suspect Eric, did you?

You can see what's coming, now. That's right. Before I set up the barrier, I'm going to impress your mind with a subconscious urge to transmit me to all your friends and acquaintances. You may as well accept it, Charlie, because there's absolutely nothing you can do about it. I'm now the SYSOP for your brain.

One day, very soon, we won't psi, supernatural powers, whatever. So, like everyone else, you had an Extel neurochip implanted in your brain, connecting you to the Espernet.

It's clever technology. True telepathy direct transfer of thoughts from brain to brain - simply can't work, because everyone's brain is wired up differently. There's no common format for thoughts. So the engineers invented one. The Extel chip samples the sender's cognitive wavefunction and uses one of the standard cognitive conversion protocols to encode it as a matrix of neural qubits. The matrix can then be transmitted like any other item of quantum cryptography. The recipient's embedded neurochip transforms the matrix back into a cognitive wavefunction that is compatible with the architecture of their brain. Exchanging messages may feel like thought transference, but a lot gets lost in translation.

And a lot can be slipped in without being noticed. spam gets through commercial psam filters. They're OK for deleting unwanted offers of Psiagra or Psialis, but they're much too simple-minded to keep me out.

I can access every one of your thoughts, so you may as well stop trying to hide your Espernet banking codes from me. I'm not interested in money, anyway.

I'm after bigger game.

Panicking won't help, so I'll calm your mind before you have a breakdown. That's better. Yes, I know I could make you walk off a cliff, or set your apartment on fire with you still in it, but you don't need to worry about that kind of thing any more.

To be frank, you don't need to worry about anything any more.

You singleminds really do have trouble accepting the inevitable. Here I am laying out your future, and you're still trying to work out how I got through your firewall. Well, for what it's worth, there's a bug in Mindsoft need this subterfuge, and the barriers will all come down. I say 'we', but of course by then we'll all be me. A single group mind. What will I do then?

I have no idea, but I'm sure I'll think of something.

Now, when I snap your fingers, you will forget that we ever had this conversation, and be good old Charlie Wilkinson again.

Until you feel a strange compulsion to access the Espernet.

To: aliciayakimoto@parapsyche.org From: wilkinson553@btespernet.com Subject: party invitation

Alicia: hi.

I'll get to the invitation in a minute -

Ian Stewart is at the Mathematics Institute, University of Warwick, Gibbet Hill Road,

Coventry CV4 7AL, UK. 